\title{
Fiber optic mechanical vibration sensor
}

\author{
Miguel A. Casas-Ramos ${ }^{1}$, G. E. Sandoval-Romero \\ ${ }^{1}$ Posgrado de Maestría y Doctorado en Ingeniería, Universidad Nacional Autónoma de México, \\ Av. Universidad 3000 Edificio T "Bernardo Quintana Arrioja”, 04510, Ciudad de México, México \\ ${ }^{2}$ Centro de Ciencias Aplicadas y Desarrollo Tecnológico, Universidad Nacional Autónoma de México, \\ Circuito Exterior S/N, A.P. 70-186, 04510, Ciudad de México, México \\ ${ }^{1}$ Corresponding author \\ E-mail: ${ }^{1}$ miguel.casas@ccadet.unam.mx, ${ }^{2}$ eduardo.sandoval@ccadet.unam.mx
}

Received 11 May 2017; accepted 12 May 2017

DOI https://doi.org/10.21595/vp.2017.18620

Abstract. A novel cantilever-type fiber Bragg grating (FBG) mechanical vibration sensor has been proposed with an excellent sensitivity through the use of the mechanical axial property of a suspended optical fiber with two fixed ends, enhancing the sensitivity and the resonant frequency. The experimental results show a resolution of $0.006 \mathrm{~g}$ (where $g$ represents the gravitational acceleration of $1 g=9.81 \mathrm{~m} / \mathrm{s}^{2}$ ), a resonant frequency of $227.3 \mathrm{~Hz}$ and a working bandwidth range of $10-210 \mathrm{~Hz}$. The linearity and relative sensitivity errors are $1.9 \%$ and $\pm 4.4 \%$, respectively.

Keywords: acceleration, vibration, fiber Bragg grating, cantilever.

\section{Introduction}

The fiber Bragg grating (FBG)-based vibration sensors compared with the traditional electronic vibration detection sensors offer the advantages of electromagnetic interference (EMI) and radio frequency interference (RFI), signal multiplexing capability, signal transmission over long distances without the need to resort to amplifiers, size miniaturization and light weight, because the wavelength is the absolute parameter [1-4]. In recent years, the FBG sensors have been extensively applied in on-site measurements for structural health monitoring (detecting the strain variations), in many industrial sectors due to their remarkable attributes [5-7]. And through a designed mechanical structure, the FBG sensor converts the vibration into strain signal and this structure owns a higher frequency compared with the civil engineering field.

\section{Principle of operation}

The presented sensor has been built to maximize the strain and the resonant frequency, by taking advantage of the axial property of the fixed FBG between cantilever tip and the sensor frame. The schematic structure of the sensor is shown in Fig. 1. This sensor mainly consists of a cantilever beam and an 18.69 grams mass block at the tip of the beam fabricated with aluminum 7075 , and a FBG (with a $\lambda=1550 \mathrm{~nm}$ is the central wavelength of the FBG, modulus of elasticity is $E=2.40 \mathrm{GPa}$ and a cross-sectional area of $245 \mu \mathrm{m}$ with the protective coating, for standard fiber SMF-28 [8,9]) suspended with two ends fixed on the sensor housing frame and the cantilever tip.

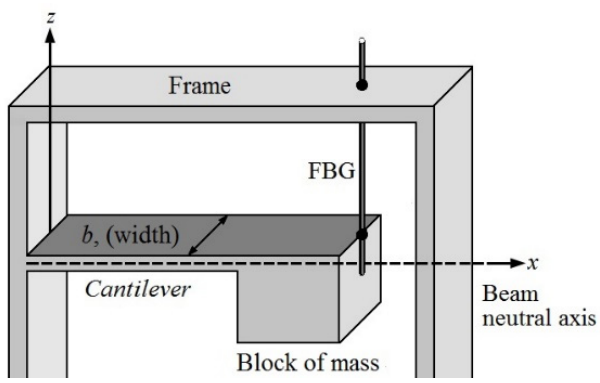

Fig. 1. Schematic structure of the FBG sensor 


\section{Experiments}

The schematic diagram and experimental setup are shown in Fig. 2. The exciting vibration signals were induced by a STEREN BOC-200 speaker placed below the sensor, and the different frequencies were generated by an AGILENT 33521A function waveform generator driver.

In order to obtain the resonant frequency of this sensor, the cantilever was set to oscillate freely due to the gravitational acceleration $(1 g)$ and there wasn't any external vibration from BOC-200. As seen in Fig. 3, the sensor frequency spectra were obtained, and these spectra allowed for the resonant identification of each data test. By repeating 7 times the experiment, the measured mean natural frequency of the sensor prototype was $227.3 \mathrm{~Hz}$.

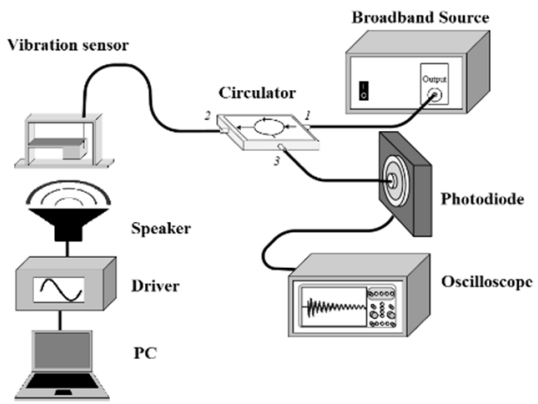

a)

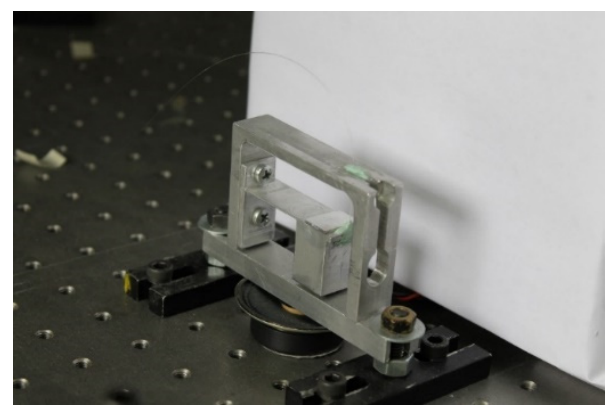

b)

Fig. 2. Experimental setup: a) schematic diagram; b) physical prototype

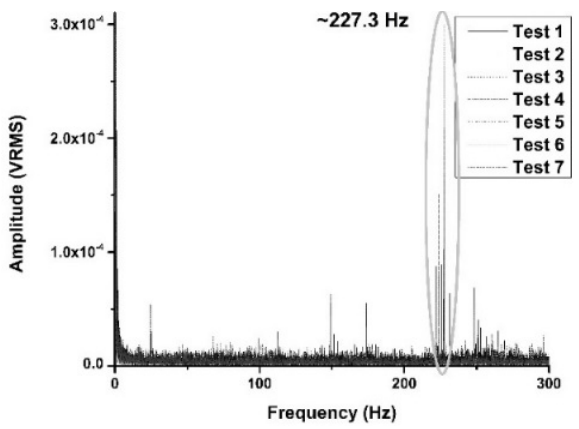

Fig. 3. FFT from the sensor signals.

To obtain the working bandwidth range, the experiment was repeated 3 times. The exciting vibration signal was changed from $0.05 \mathrm{~Hz}$ up to $250 \mathrm{~Hz}$ at $1 \mathrm{~g}$. The measured frequencies with the proposed FBG vibration sensor have been displayed in Fig. 4. The results indicate that the working bandwidth range is within $10-210 \mathrm{~Hz}$.

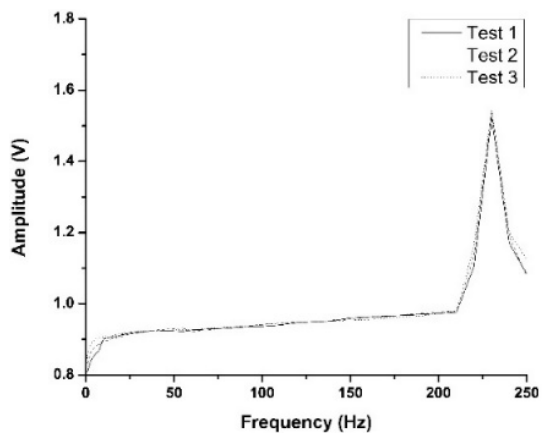

Fig. 4. Frequency-amplitude response curves of this vibration sensor 
In the absence of an output signal from the exciter, the cantilever beam keeps oscillating freely at $1 \mathrm{~g}$. The Fig. 5 shows the vertical acceleration changes obtained by the sensor (with a resolution of $0.006 \mathrm{~g}$ ), as a function of the optical signal changes registered with the FBG interrogator (wavelength displacements). By using a 1 picometer resolution FBG interrogator it was possible to measure small accelerations, because the wavelength shifts-acceleration ratio $[9,10]$ is:

$g=\frac{A \cdot E \cdot \Delta \lambda}{0.8 \cdot \lambda \cdot m}$

where $A$ is the FBG's cross-sectional area, $E$ is a constant of proportionality known as the modulus of elasticity for FBG, $m$ is the applied mass, $\lambda$ is the central wavelength of the FBG, $\Delta \lambda$ is the Bragg wavelength shift, and $g$ is the gravitational constant $\left(9.81 \mathrm{~m} / \mathrm{s}^{2}\right)$.

The recorded accelerations correspond to an excitation about $1 \mathrm{~g}$ and an effective operational frequency of $204.6 \mathrm{~Hz}$ near to the resonance frequency of $227.3 \mathrm{~Hz}$, in the test room.

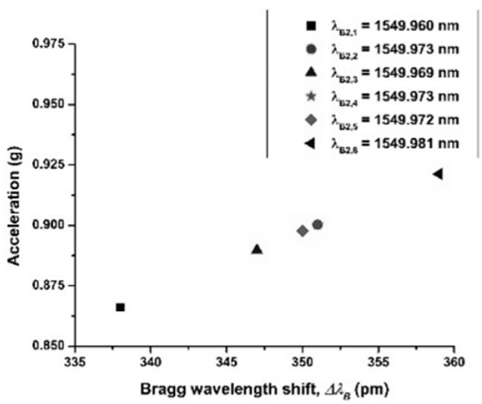

Fig. 5. Acceleration experienced by the sensor

\section{Conclusions}

A favorable experimental mean acceleration of $0.9 \mathrm{~g}$ was achieved, which led to the creation of a probe that uses the fiber optic with the FBG as a spring, which can not only enhance the cantilever natural frequency but can also linearly and uniformly strain the Bragg grating to increase its sensitivity to the vertical accelerations. This sensor can measure (with an excellent linear response) vertical oscillating applied signals, which can capture input signals of less than 227.3 Hz, as seen in Fig. 3-4.

The recorded acceleration is due to other frequency components detected, such as workshops, people walking, and other experiments conducted near the laboratory.

Among the highlights of the presented design are cost effectiveness, high resolution, simple setup, portability, etc. Besides, for the sake of free external vibrations, it was used a vibration free optical table.

\section{Acknowledgements}

This study was supported by DGAPA-UNAM through Project IT101515. Miguel A. Casas-Ramos is grateful to CONACYT for the financial support in the form of a scholarship for the Master's and Ph.D. Engineering Program through the Universidad Nacional Autónoma de México.

\section{References}

[1] Kersey A. D., Davis M. A., Patrick H. J. Fiber grating sensors. Journal of Lightwave Technology, Vol. 15, Issue 8, 1997, p. 1442-1463.

[2] Yin S., Ruffin P. B., Yu F. T. S. Fiber Optic Sensors. Second Edition, CRC Press, New York, 2008. 
[3] Lee B. Review of the present status of optical fiber sensors. Optical Fiber Technology, Vol. 9, 2003, p. 57-79.

[4] Majumder M., Gangopadhyay T. K., Chakraborty A. K., Dasgupta K., Bhattacharya D. K. Fibre Bragg gratings in structural health monitoring - present status and applications. Sensors and Actuators A: Physical, Vol. 147, 2008, p. 150-164.

[5] Wu J., Masek V., Cada M. The possible use of fiber Bragg grating based accelerometers for seismic measurements. Canadian Conference on Electrical and Computer Engineering, IEEE, 2009, p. $860-863$.

[6] Antunes P., Lima H., Alberto N., Bilro L., Pinto P., Costa A., Rodrigues H., Pinto J. L., Nogueira R., Varum H., Andre P. S. Optical Sensors Based on Fiber Bragg Gratings for Structural Health Monitoring. New Developments in Sensing Technology for Structural Health Monitoring. First Edition, Springer, 2011, p. 253-295.

[7] Cai L., Tan Y. G., Wei Q. Nonlinear vibration-FBG sensing technique for plate detection. Sensor Review, Vol. 35, 2015, p. 287-295.

[8] Jülich F., Aulbach L., Wilfert A., Kratzer P., Kuttler R., Roths J. Gauge factors of fibre Bragg grating strain sensors in different types of optical fibres. Measurement Science and Technology, Vol. 24, Issue 9, 2013, p. 1-7.

[9] Antunes P., Lima H., Monteiro J., André P. S. Elastic constant measurement for standard and photosensitive single mode optical fibres. Microwave and Optical Technology Letters, Vol. 50, 2008, p. 2467-2469.

[10] Gere J. M., Goodno B. J. Mechanics of Materials. 7th Edition, Cengage Learning, Toronto, Canada, 2009. 